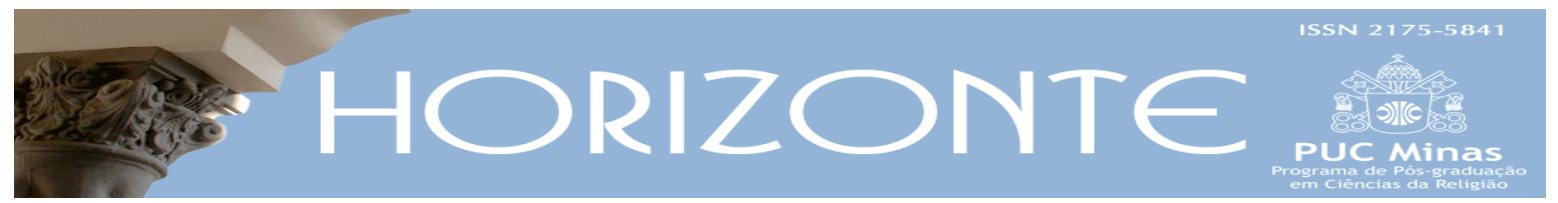

Dossiê: Paradigma pós-religional - Artigo original

(@) $\odot \Theta$

DOI - 10.5752/P.2175-5841.2015v13n37p379

\title{
A religião sob o domínio da estética
}

\author{
The religion under the rule of aesthetics
}

\begin{abstract}
Resumo
O presente artigo analisa o moderno processo de estetização da cultura e da religião como desdobramento consequente da expansão da racionalidade do mercado para a vida subjetiva e a esfera libidinal dos sujeitos. Seu principal objetivo é indagar acerca do futuro da religião sob o impacto da cultura da sensação e da inflação do estético. Em primeiro lugar, com a ajuda dos estudos de Türcke, Welsch, Foucault e Schultze aborda o processo de estetização da vida social, suas causas e características; em segundo lugar, seguindo Dufour, Türcke Leiss, Kline, Jhally e Welsch, indaga de que forma a dinâmica da estetização impacta o cotidiano e a economia bio-psíquica das pessoas; em terceiro lugar aplica os resultados alcançados na análise do que está acontecendo com a religião sob o domínio da estética e da cultura do sensacional. Por fim, pergunta sobre os possíveis potenciais emancipatórios da própria experiência religiosa estetizada e tenta tirar algumas consequências futuras para a religião sob o domínio da estética.
\end{abstract}

Palavras-chave: Estetização; estética; religião; capitalismo; mudança cultural.

\begin{abstract}
This article examines the modern process of aestheticization of culture and religion as consequent unfolding of the expansion of market rationality to the subjective life and the libidinal sphere of subjects. Its main objective is to inquire about the future of religion under the impact of sensation seeking culture and the inflation of aesthetics. Firstly, with the help of Türcke, Welsch, Foucault and Schultze's investigate the aestheticization process of of social life, its causes and characteristics; Secondly, following Dufour, Türcke Leiss, Kline, Jhally e Welsch, it asks how the dynamics of aesthetical impacts the daily life and the bio-psychic economy of people; thirdly, it applies the results obtained to the analysis of what is happening with religion under the regime of aesthetics and sensational culture. Finally, it asks about the possible emancipatory potential of aestheticized own religious experience and tries to draw some further consequences for religion in the aesthetic field.
\end{abstract}

Keywords: Aestheticization; aesthetics; religion; capitalism; cultural change.

Artigo recebido em 12 de novembro de 2014 e aprovado em 06 de março de 2015.

*Doutor em Teologia Católica e Professor Adjunto do Programa de Pós Graduação Stricto Sensu em Ciência da Religião da Universidade Católica de Goiás. País de origem: Brasil. E-mail: alberto-moreira@uol.com.br 


\section{Introdução}

Parece típica da moderna racionalidade sistêmica a necessidade, em vista do seu possível controle, de manter em dia a predicabilidade dos processos sociais, culturais, econômicos. Sabemos que da administração dos boatos, dos antropomórficos humores variantes das ações na Bolsa e da instabilidade constitutiva dos mercados financeiros, vive e floresce o ramo muito rentável dos "mercados futuros" e até as menos glamourosas bolsas de apostas. Para desgosto dos pós-modernos, apesar da sua ênfase no fragmentário e no descontínuo, continua muito forte, não só na economia, mas também nas ciências sociais, a tentativa de elaborar esquemas explicativos de longa duração e assim, pelo menos provisoriamente, tentar conferir inteligibilidade não apenas à parte, mas também aos rumos do todo. Se por parte dos estrategistas do sistema financeiro tal intento pode ser admitido, sem o menor rubor, como vontade de poder e riqueza via controle da informação, uma ciência social que se propõe crítica e autocrítica precisa garantir, teórica e praticamente, que seu intento está a serviço de um possível aumento na liberdade e na autonomia dos sujeitos. Assim, as subsequentes reflexões sobre transformações em curso no campo religioso e tendências que elas apontam para o futuro, não querem ser entendidas nem como profecia nem como modelos matemáticos, mas como análise provisória, que tenda dar conta de uma modalidade inusitada do deslocamento do religioso, e se possível apontar para transformações mais amplas na própria cultura e sociedade, onde esta experiência religiosa é vivida (Moreira, 2008b). Nunca é demais realçar um lembrete de Prandi de que uma boa teoria sociológica da religião (enfoque deste artigo) exigiria uma boa teoria da sociedade, mas esta ainda está por ser feita.

O ponto de partida, portanto, são as transformações do religioso, e não o seu fim. Por outro lado, também é possível que depois de tantas transformações alguém sinta dificuldade em reconhecer a "religião", ou pelo menos a religião tal como a conheceu. Transformações ou mudanças duradouras no campo religioso podem ser observadas, por exemplo, em sua imbricação com os processos acelerados de globalização econômica, cultural e política. Algumas delas são: a 
interpenetração da religião com a nova ordem global, a proximidade de fronteiras entre os sistemas simbólicos, a hibridização das práticas e sistemas religiosos, o pluralismo religioso, a midiatização da religião, o surgimento de espiritualidades laicas, a flutuação ou falta de ancoragem geográfica das religiões, a crise das mediações institucionais (não de todas!), o surgimento de novos intermediários especializados, entre outras (Moreira, 2008a). Em plena vigência dessas mudanças supõe-se que não podemos falar da "religião" como uma entidade abstrata ou essência imutável, que pairaria eterna para além de todas as formas históricas de sua encarnação. As religiões só existem no plural, mesmo se como recurso simplificador usemos o singular. A própria facticidade histórica da pluralidade de suas formas deveria nos alertar de que -para usar o tradicional esquema funcionalista - se num determinado contexto as religiões podem ter assumido certas "funções sociais", por exemplo, a de códigos reguladores do comportamento coletivo em sociedades agrárias do passado, nada impede, em princípio, de que possam assumir "novas” funções ou papéis quando há mudanças profundas nas formações sociais.

Religiões realizam deslocamentos, bricolagens, combinações ou espichamentos a partir de dentro de seus próprios códigos simbólicos. Por outro lado, nada garante, em princípio, que outras instâncias sociais não possam assumir "funções" ou papéis até então atribuídos a elas. Isso faz atualmente, por exemplo,o marketing, ao determinar, com enorme credibilidade, em que consiste a máxima felicidade do gênero humano. Religiões podem ser, portanto, também deslocadas ou realocadas a partir de elementos “de fora” delas mesmas. A situação quotidiana é a terceira, na qual as religiões, como sistemas simbólicos mutantes e conservadores, interagem o tempo todo com o seu "ambiente".

Por tudo isso, prefiro falar em deslocamentos e transformações do religioso, pois a complexidade e amplitude desses processos talvez não permita resumi-los ainda em categorias sintéticas, como esta do “paradigma pós-religional”, que pouco revela das reais transformações em curso e pressupõe que todas as formas 
concretas possam ser integradas num "paradigma”.

Seja como for, parece inegável que processos de longa duração estão afetando toda a vida social e, portanto, também as práticas e crenças religiosas das pessoas. O mais importante deles tem a ver com o surgimento da sociedade da sensação (TÜRCKE, 2010), da qual quero tratar apenas seu aspecto mais evidente: a estetização crescente da vida cotidiana. Vivemos desde algum tempo sob uma torrente de estímulos das tecnologias e meios de comunicação e ela se traduz culturalmente pelo boom da estética: há uma expectativa e cobrança de que tudo seja atraente, bonito, agradável, confortável, prazeroso, diet, light, fashion, soft, com muito design, image, look, performance e estilo. A compulsão estética vai da roupa, da decoração, dos carros e das embalagens, até os desenhos animados para crianças (como o mega-sucesso Frozen, da Disney), à imagem construída dos políticos, ao selfie dos narcisos, às logomarcas onipresentes, à dramática performance dos pregadores e à intensa emoção de quem submerge no transe do gospel, nos shows-missa e nos grandes espetáculos religiosos de massa. Na literatura e no cinema, história e religião são constantemente estetizadas, como no O nome da Rosa, o Código da Vinci ou no recente Noé. Parece que cada vez mais dimensões da realidade são estetizadas e que a própria realidade tornou-se uma construção estética. A vida deve ser show, e assim também deve ser a religião, o show da vida.

Neste $\operatorname{artigo}^{1}$ gostaria de abordar o processo de estetização da vida social, de como sua dinâmica é reforçada por desenvolvimentos situados fora do campo do próprio estético, para em seguida refletir como a dinâmica da estetização atinge o campo religioso; por último, tento tirar algumas consequências ou tendências para o futuro da religião sob o domínio da estética. Apesar das ligações evidentes, não abordarei a questão da estética na arte, pois além de exceder em muito os limites desse artigo, "a estética importante é hoje a estética fora da estética” (WELSCH, 1996, p. 12, grifos do autor), aquela que se dá na política, na cultura, na mídia, na

\footnotetext{
${ }^{1}$ Uma versão inicial deste texto foi apresentada no VI Congresso Internacional em Ciências da Religião da PUC Goiás (MOREIRA; LEMOS; QUADROS, 2014).
} 
comunicação, na ciência e na construção das subjetividades. Seja então posta a questão provocativa: Será que num mundo sempre mais administrado pela racionalidade unidimensional (do mercado) o futuro da religião é tornar-se estética?

\section{0 que significa estetização da realidade?}

A Estética (Aisthesis = sensação/percepção, impressão deixada pela percepção) tem a ver com a percepção da beleza sensível e com a emoção interna quando se capta e se frui a beleza e a harmonia nas imagens e percepções sensoriais. Assim, pode-se dizer que estetizar é tentar produzir essa experiência de beleza, é intensificar as percepções sensoriais de modo a produzir nas pessoas a emoção ou comoção interna causada pela vivência da beleza. Essa vivência sensacional da beleza, ou arrebatamento estético, pode-se dar em detrimento do conteúdo ou independentemente do significado "objetivo" das coisas e da situação. Começo então com uma definição provisória, que será retomada no final: estetização é um processo pelo qual se quer dotar de valor estético um objeto, um lugar, um entorno ou uma experiência que por si só não teriam tal valor. Como veremos, esse conceito de estetização se aplica a camadas diferentes da realidade e se refere não tanto a um fato fixo ou definitivo, mas a uma dinâmica sócio cultural que se modifica, e que modifica tudo o que nela se encontra. A religião, mesmo tendo desde sempre uma linguagem e expressão estética, também está sendo profundamente modificada por essa dinâmica sócio-cultural, que incide desde fora sobre o campo religioso e que coopta e reorganiza a religião segundo os termos de sua própria gramática.

W. Welsch (1993; 1996), ao oferecer uma tipologia dos processos de estetização social, menciona uma estetização mais superficial, fácil de perceber e criticar, e uma estetização mais profunda, não tão visível, embora mais importante e com mais consequências para a vida social e a experiência religiosa. Na estetização superficial trata-se de um embelezamento, de uma operação plástica na 
realidade, que envolve tanto um upgrade estético, um face lifting das pessoas e paisagens, ruas e bairros, fachadas e lojas, ambientes internos e externos, carros e decoração, roupas e estilos de vida, objetos e mercadorias, como também de um esforço consciente para aumentar a animação, as emoções e as sensações que se podem experimentar vivendo nesses espaços, praticando tais estilos de vida ou usando tais objetos ou mercadorias. Ir ao shopping, a um restaurante ou local turístico passa a ser algo emocionante; a vivência emocional e o entretenimento tornam-se as linhas básicas da atividade cultural; predomina o valor estético mais imediato na forma do prazer, da diversão, da experimentação e do gozo sem consequências. Esta cosmética da realidade responde ainda a uma necessidade elementar do ser humano, de transformar a si mesmo, a paisagens, coisas e situações para que sejam ou pareçam mais bonitas, mais harmônicas e agradáveis aos sentidos. Afinal, o moderno quer se contrapor a uma tradição (religiosa) anterior, hoje nada em moda, que enfatizava a ascese, o pudor vitoriano, o rígido controle sobre as linguagens estéticas na arte, no uso do corpo e na vida cotidiana.

Aliás, como sabemos, a modernidade se caracteriza, segundo Max Weber, exatamente pela independência das esferas da arte, da ciência e da moral que antes estavam todas incrustadas na religião (WEBER, 1922). No entanto, essa autonomização da arte em relação à esfera da religião custou um preço alto: sua adoção pelo mercado. Conforme pontua Zamora:

Na época liberal-burguesa a autonomia da arte e da cultura é inseparável do seu processo de conversão progressiva em mercadoria, que se por um lado possibilita a liberdade frente à instituição eclesiástica e ao mecenato aristocrático, cria, por outro lado, uma dependência com respeito ao mercado, às suas preferências e exigências. (ZAMORA, 2014, p. 301).

Assim, a tendência de melhorar a vida através do embelezamento expandiuse e mudou radicalmente ao ser assumida pela dinâmica do mercado. O mito do progresso, a pressão mercadológica e a crescente força social da ciência e da tecnologia deram a essa necessidade de aparelhamento, de embelezamento e cosmética do mundo, da cidade e do homem, formas nunca imaginadas. A tendência se tornou dominante, a estetização foi assumida como estratégia 
econômica e o hedonismo, que em si não era novo, se tornou uma matriz cultural. Em nossa sociedade o lazer, a experiência estética e a busca da beleza se tornaram atividades profissionais cuidadosamente planejadas e administradas, que envolvem instituições poderosas, pessoal altamente especializado e imensas somas de dinheiro. A ambientação social está marcada desde os anos da infância pela publicidade e pelo marketing. Como mostraram Leiss, Kline e Jhally (1997), a publicidade de há muito não é apenas um setor da economia encarregado de turbinar as vendas, mas é uma cultura na qual se nasce e se vive, uma ambiência que, ao substituir as culturas tradicionais, praticamente se naturalizou. Justamente por isso, a publicidade não visa fundamentalmente vender um determinado produto, mas produzir fidelidades de longo prazo, inculcar o próprio consumo como modo de vida e horizonte da existência. A publicidade "educa" as multidões no apetite insaciável por bens, novas sensações e experiências (LASCH, 1989, p. 137). Ela disciplina até nossa economia libidinal, e seria impensável sem o uso inteligente e refinado da linguagem estética e artística. Portanto, não há espontaneidade no sorriso espontâneo da top model, assim como não há nenhuma magia na gestão milionária dos mágicos filmes da Disney: o que existe é uma produção industrial da beleza e do encantamento.

Welsch (1996) afirma que houve uma inversão entre mercadoria e embalagem, entre essência e aparência, entre hardware e software. A coisa em si tornou-se acessório, a estética em torno dela tornou-se o principal. Por isso todos os produtos passam regularmente por fases periódicas de embelezamento e estetização, para que as mercadorias não percam seu poder de atração e fascínio. Mas como isso é possível? O marketing, indo muito além das vitrines dos antigos boulevards, através do design e do emprego contínuo dos artistas plásticos ou visuais, se encarregou de amorizar o comprador com o objeto, de criar nos passantes o que W. Benjamin chamou de empatia com a mercadoria (1972, p. 561, 1178). O indivíduo se encanta e se enamora da mercadoria - que em si geralmente é algo morto - porque na superfície lisa, brilhante e colorida dos objetos estão calados e reduzidos ao silêncio todo o sofrimento e a alienação embutidos no 
processo social de sua produção. A entusiástica adesão ou doação de si da pessoa à superfície cuidadosamente estetizada da mercadoria doa a esta uma alma, enquanto o comprador perde a sua. Ao deixar-se seduzir, ele se objetifica; ao esquecer-se dos custos humanos, sociais e ambientais, habilmente ocultos pela estética, ele se aliena.

O melhor exemplo para essa inversão entre conteúdo e forma, entre o produto e sua embalagem, é o spot publicitário. Na extrema concentração de tempo, na concisão da linguagem, na ideia certeira, na novidade, no uso das cores e da simbologia subliminar e de todos os recursos da criatividade artística, o comercial produz uma alta eletrização estética (TÜRCKE, 2010, p. 27). Ele é tanto forma artística como material e estímulo do consumo; a primeira a serviço do segundo; mais do que isso: o comercial se estabeleceu como modelo de comunicação e percepção, um laboratório estético-psicológico-fisiológico para transmitir informação e sensação de forma mais econômica, porque mais intensiva (TÜRCKE, 2010, p. 28). O marketing e o design fazem parte essencial do processo de construção estético-simbólica da aura das mercadorias, esta entidade metafísica, ou valor simbólico agregado, que está incorporado e representado iconicamente nas marcas. Se para Benjamin (2012), a aura das mercadorias é uma versão secularizada e mercantilizada da aura espiritual, poderíamos dizer, seguindo a analogia, que há um processo estético-simbólico de santificação das marcas. Elas devem incorporar, provocar e representar qualidades e virtudes, valores e emoções... sensacionais. Uma vez construída a aura, a imagem, aquele agregado de atributos metafísicos adere às marcas e lhes deveria garantir uma vida (quase) eterna no mundo infernal da concorrência mercadológica. Devido ao seu poder sutil e eficaz de convencimento, faz tempo que as religiões e igrejas lançam mão dos mil e um recursos da publicidade e da comunicação social. Afinal, em termos de construção da imagem, vender um carro é o mesmo que vender um político ou um líder religioso.

Estetização da vida cotidiana (uma hipótese proposta por Scott Lash, John Urry e Mike Featherstone) supõe que a experiência cotidiana está cada vez mais 
estetizada e nosso consumo está cada vez mais cativo do design e da estilística. Por causa da publicidade e da natureza publicitária da mídia, "a estética se tornou um valor condutor autônomo... a estética, em suma, não é apenas o veículo, mas antes a essência” (WELSCH, 1996, p. 4). Nesse sentido, o processo de estetização tornou-se cultivo coletivo, e como tal faz parte das estratégias de produção social do esquecimento e da reprodução do consentimento.

Aqui já fomos muito além do mero campo das relações econômicas. Chegamos ao nível mais profundo do processo de estetização da vida cotidiana, no qual a estética se torna a prioridade da vida social e pessoal. Para se chegar a esse estágio cultural, a esta ambiência social, foi necessário um acelerado processo de mudanças no processo produtivo e o emprego sistemático de novas tecnologias. Há uma base material que sustentou e sustenta tais mudanças culturais; elas não teriam ocorrido dessa forma sem a incorporação sistemática da tecnociência e do marketing ao processo produtivo capitalista. As tecnologias computacionais integraram a simulação como parte constitutiva do planejamento e da fabricação das mercadorias. A simulação, através do emprego de modelos matemáticos e da digitalização da informação, mudou completamente a noção do que existe e do que pode existir. Não se trata mais de imitar a realidade, ou de reproduzi-la graficamente através de algoritmos e equações, mas de projetar realidades inexistentes e criá-las virtualmente, da forma que se queira, para então produzir industrialmente o que vai ser realidade amanhã, na vida real dos consumidores. Dessa maneira, a estética passou da superestrutura para a base material da sociedade (WELSCH, 1996, p. 4). Agora, a estetização do real potencialmente não conhece mais limites.

Mas essa forma de estetização material e tecnológica, e nossa convivência com ela, produziram também uma estetização imaterial, das consciências e da nossa apreensão da realidade como um todo. $\mathrm{O}$ cinema, a cultura imagética, o design, a mídia de massa com seus reality shows, mas hoje sobretudo os programas de computador, os jogos, sites e plataformas interativas na Internet do 
tipo second life, nas quais os participantes assumem avatares e montam tanto aparências como personalidades, todas essas "agências" também desmaterializam e modelam constantemente a realidade; elas nos ensinaram que a realidade na sua própria substância é virtual, manipulável e esteticamente modelável:

Tanto no nível material como no social, a realidade está se revelando ela mesma, como conseqüência das novas tecnologias ... como sendo cada vez mais determinada pelos processos de estetização; ela está se tornando sempre mais uma questão estética - estética tomada aqui, é claro, não no sentido de beleza, mas antes de virtualidade e modelabilidade (WELSCH, 1996, p. 7).

Desnecessário dizer que tais mudanças, ao se difundirem como cultura e ambiência, impactam fortemente o tipo de humano que está sendo produzido ou "modelado". Um novo ser humano está sendo gestado, um novo indivíduo - para não desgastar ainda mais o conceito de sujeito - está sendo "estilizado", no seu corpo, na sua mente e na sua alma. A estetização dos corpos e da fantasia segundo modelos virtuais, como Barbie, Batman ou as princesas da Disney começa bem cedo. Normal no mundo dos adultos é a busca mais ou menos obsessiva pelo corpo perfeito, pela beleza e juventude nas clínicas de cirurgia plástica, nos centros, academias e programas especializados em rejuvenescimento, emagrecimento, alinhamento e modelagem corporal e pelo uso corriqueiro dos milhares de produtos da indústria de cosméticos. A hipervaloração estética da aparência e da juventude induz sem muito alarde a uma valoração moral, enquanto modelo performático de humano, do jovem e do adolescente em relação às outras faixas etárias. Além disso, como não basta ser, mas é preciso aparecer, o indivíduo experimenta uma verdadeira obsessão pelo mostrar-se (o show dos selfies). Esse est percipi, quem não é percebido não existe de forma alguma: "não emitir é equivalente a não ser - não apenas sentir o horror vacui da ociosidade, mas ser tomado da sensação de simplesmente não existir" (TÜRCKE, 2010, p. 45). Daí a compulsão generalizada para emitir adquiriu forma estética; é a maneira de garantir ser notado e ter direito de cidadania, ainda que o exibido seja apenas as entranhas do próprio vazio oferecido à degustação geral. Nossa cultura da extrojeção compulsória e publicizada da intimidade, que se esparrama pelos 
outdoors e shows midiáticos de domingo, garante que quem aparece na telinha não é tolo. E o principal: vai ficar famoso. Inversamente, "quem não tem sensações não é. [...] Se não pode mais sentir é porque está morto” (TÜRCKE, 2010, p. 65). O afogamento na torrente de estímulos vem da "vontade de sentir a si próprio, de se certificar que se existe, para sair do vácuo da falta de percepção, de sensação e de sentimento" (TÜRCKE, 2010, p. 67). Ao cultivar massivamente essa sensation seeking 2 o sistema capitalista vai criando "eus" exibicionistas, narcísicos e infantis, inteligentes, mas intolerantes; cheios de aptidões técnicas, mas geralmente insensíveis ao sofrimento dos outros, além de dispostos ao uso da violência se contrariados. A raiva e o quebra-quebra podem ser sinais invertidos de uma sensation seeking desesperada. Dany-Robert Dufour, que estuda o advento do novo humano gestado pelo neoliberalismo, chamou tais grupos de as novas manadas gregárias (DUFOUR 2009; 2011).

\section{Estetização e redução da complexidade social}

A estetização da vida cotidiana é um dos resultados das transformações causadas pela modernização da sociedade. Uma das forças que mais a impulsionaram do ponto de vista cultural foi a dinâmica acelerada da individualização. O processo de modernização e destradicionalização dos últimos cem anos diluiu e enfraqueceu os laços que prendiam as pessoas à solidariedade orgânica vigente nas sociedades tradicionais, favorecendo a individualização. Aliados ao posterior enfraquecimento das grandes mediações coletivas e identitárias, como classe, partidos, igrejas e sindicatos, tais processos foram movidos pela expansão da economia de mercado e foram condições básicas para que surgisse a sociedade dos indivíduos. Nossas sociedades se tornaram conglomerados funcionais de indivíduos, cada vez mais sobrecarregados com a tarefa de escolher e prover sua

\footnotetext{
${ }^{2}$ Por sensation seeking (busca de sensações) C. Türcke (2010, p. 66s.) se refere a uma compulsão existencial de massa que leva os indivíduos a buscar o choque áudio-visual, a submergir na torrente de estímulos eletrônico-midiáticos, a curtir obsessivamente a excitação do espetacular e das vivências sensacionais. Com o tempo cria-se uma dormência, um anestesiamento, que gera um vazio, uma falta de sensações que leva à busca de estímulos ainda mais fortes.
} 
própria vida, tanto de bens materiais, recursos, capacidades, relações humanas e habilidades, como de sentido e de felicidade.

Surge, então, uma situação contraditória: por um lado os indivíduos se encontram cada vez mais sozinhos e mais obrigados a escolher "livremente" o trabalho, a companheira, os amigos, o lugar de moradia, o estudo, o que vestir, pensar, sentir, comer e beber. Por outro lado, ao realizar todas essas tarefas, eles(as) fazem parte de uma massa de indivíduos com quem compartilham objetivamente a mesma condição existencial. Todavia, essa condição objetiva comum não faz surgir entre eles algo como uma "consciência de classe" ou uma solidariedade orgânica. Isto porque o recente processo de modernização provocou uma desintegração dos ambientes e dos mundos ligados a uma classe social específica, que tinha pontos de orientação coletiva claros e tangíveis. Como consequência, os indivíduos se orientam cada vez mais segundo esquemas estéticos de estilo de vida, baseados na idade, no seu capital educacional (NIELSEN, 2008, p. 9) e, é claro, também na renda. Se não há, conforme Bauman (1998), como fugir da obrigação de escolher, imposta pelo sistema, em que sentido são feitas as escolhas e as decisões dos indivíduos? A tese de G. Schultze (1997) é esta: os indivíduos orientam-se sempre mais por critérios estéticos, por aquilo que consideram subjetivamente uma "vida boa", uma vida de satisfação e prazer.

Para Schultze (1997), em sociedades ricas, que alcançam um relativo excedente de produtividade e de tempo livre, as pessoas se voltam para outro tipo de necessidades, as subjetivas. No entanto, é dramático observar que nas sociedades periféricas ou nas periferias das sociedades opulentas também aquelas pessoas que não têm nenhum excedente de produtividade e cuja base material de existência está em constante risco de colapso, ou seja, os pobres e muito pobres, também eles não escapam à lógica estetizadora e escravizadora da realidade. Pelo contrário, parecem estar até mais seduzidas pelo fascínio e empoderamento simbólico aliados às marcas e à sua construção estética. 
Georg Simmel, nos inícios do século XX, já afirmava que a expansão secular da busca por satisfação e prazer constituía um momento central da subjetividade moderna (SIMMEL, 1900 apud SCHULTZE, 1997, p. 38). Mas para Nielsen (2008), o que mais caracteriza e reforça o processo de estetização nas sociedades modernas é o fato de que a vivência estética possibilita uma estilização redutora da complexidade e por isso ela serve como uma terapêutica para as dolorosas ambivalências da modernidade:

A mistura difusa de várias e incompatíveis formas de prática e experiência na vida cotidiana moderna - que interferem e desarticulam umas às outras, resultando em distração e perda de orientação - é transformada em perfis, emoções e conflitos claramente definidos no espaço vivencial da prática estética. A experiência heterógena e ambivalente da modernidade é submetida a uma sintetização que a torna acessível tanto à vivência intensa como à reflexão concentrada (NIELSEN, 2008, p. 7).

O processo de estetização do cotidiano é marcado pela aplicação do apelo às qualidades sensoriais e emocionais da experiência a todas as relações e âmbitos sociais, o que implica transcender os limites discursivos e institucionais. A busca pela experiência estética, sensorial e emocional, funciona no dia a dia como um potente redutor da fragmentação e da complexidade desorientadora da cultura contemporânea. Para Nielsen, o que contribuiu para que este tipo de estetização tenha alcançado um status quase hegemônico se deve à sua habilidade para canalizar uma multiplicidade heterogênea e desencontrada de dinâmicas, presentes na cultura e na sociedade atual (NIELSEN, 2008, p. 8-9). A experiência estética é, sobretudo, síntese, sintetização pré-reflexiva, intuitiva e sensorial (mas não irracional) de um impacto, de uma pegada para a qual concorrem pulsões, afetos, apelos, razões, explicações ou sentidos desenfeixados, desencontrados, quando não contraditórios. Quem precisa geri-la é sempre uma subjetividade. Na esteira da crise das instituições tradicionais produtoras de explicação e sentido (família, religião, escola, Estado e mediações coletivas), são os indivíduos que se encarregam sempre mais da tarefa. O sujeito se torna administrador de sua própria subjetividade, manager de seu próprio mundo interior, seguindo a racionalidade 
estética da vivência prazerosa. Nessa estratégia subjetiva, as situações e os objetos exteriores são manipulados de forma mais ou menos planejada e consciente para trazer ao sujeito sensações intensas, vivências de satisfação e prazer. Para Schultze (1997), isso se tornou, pela repetição e rotina, uma cultura, uma disposição coletiva duradoura, que o autor denomina de racionalidade das "vivências sensacionais" (SCHULTZE, 1997, p. 40).

Schultze considera que o princípio estético do sensacional domina a economia psicofísica das pessoas e foi assumido estruturalmente no funcionamento das instâncias que provêm o público de tais experiências prazerosas, que são, sobretudo, o mercado, mas também as políticas públicas de arte e cultura. Nisso coincide com a crítica de Türcke (2010), que analisa por um viés fisiológico, psicanalítico e teológico a sociedade excitada, ou das sensações, como a forma mais acabada do capitalismo. Trata-se de uma sociedade que se automodela (e muito esconde) em busca de vivências sensacionais, emocionantes e prazerosas. Justamente aqui insere-se o princípio básico da estetização da vida cotidiana: a busca sistemática dos indivíduos por experiências que lhes tragam satisfação, emoção e prazer. Não se trata, portanto, apenas de uma mentalidade ou de um puro hedonismo, que procura em tudo sempre mais diversão e prazer (no sentido de entretenimento dado por Postman, 1985).

O indivíduo não experimenta a noção de beleza ou suas preferências de gosto como algo que lhe sobrevém do exterior, e sim como características que ele projeta nas situações e nos objetos que consome. O sujeito tenta organizar e montar as condições de tal modo, para "que ele ache tudo uma "beleza" (SCHULTZE, 1997, p. 40). Ou seja, independentemente do estilo e gostos serem considerados como "alta cultura" ou "brega chique", a referência é sempre mais o próprio indivíduo. Como dito acima, ele se torna um administrador de suas próprias vivências sensacionais, um gestor da própria economia psíco-física, mas sem aquele aspecto de autonomia dado por Foucault ao conceito de tecnologias do eu (FOUCAULT, 1990). Essa gestão do self para alcançar a satisfação e viver experiências subjetivas de autoafirmação, segue a racionalidade típica da 
modernidade, que organiza os meios para alcançar determinado fim. É importante perceber dois aspectos desse processo: primeiro, são os indivíduos que mobilizam sua vida interior, suas energias e potencialidades para alcançar os fins (estéticos) que se determinam. Em segundo lugar, ao mobilizar seus recursos subjetivos, o indivíduo está buscando o que lhe causa emoção, o que provoca subjetivamente mais contentamento e satisfação. Ambos os aspectos reforçam a orientação para dentro, para a subjetividade dos indivíduos - é ela que determina as escolhas, muito mais do que os aspectos voltados para a exterioridade e a funcionalidade das mercadorias, dos bens e das situações buscadas. Já vimos que não é a necessidade objetiva do indivíduo e nem a utilidade prática oferecida por uma mercadoria que determinam a escolha por uma determinada marca ou modelo dentre os muitos disponíveis, mas a expectativa subjetiva de desfrute e satisfação associada a ele. Desnecessário dizer, por outro lado, que essa subjetividade foi formada e educada anteriormente pela cultura e ambiência da sociedade produtora de mercadorias. Trata-se tanto de uma motivação exterior como interior.

Não está se dizendo que a estética abarca tudo e tudo na vida social seria determinado esteticamente. Da mesma forma, aquelas ações e decisões cotidianas das pessoas, voltadas para suas necessidades imediatas e pragmáticas continuam, como usar óculos, comprar sabonete, colocar filhos na escola, ir à igreja, comer, morar, etc. No entanto, aquilo que vai além dessa funcionalidade imediata, como escolher modelo, marca, bairro, localização, reputação, material, aparência, cheiro, fama obedece a critérios subjetivos que não têm nada a ver com o valor de uso da coisa concreta, mas com a sensação interior de satisfação esperada pelo sujeito da sua opção de compra.

No entanto, do outro lado estão todas as instâncias e instituições que vendem, oferecem ou prometem tais experiências prazerosas. Ou seja, os fabricantes, provedores e fornecedores de todos os tipos imagináveis de mercadorias, bens e serviços, inclusive públicos, toda a indústria cultural, do lazer, do barbeiro à agência de viagens, da moda aos festivais de música, da grande mídia 
ao supermercado da esquina, sem esquecer as igrejas. Todas essas instâncias que prometem prazer e emoção, ao contrário dos indivíduos, funcionam segundo critérios de uma racionalidade voltada para o exterior e obedecem a rígidos parâmetros de funcionalidade capitalista. Os agentes fornecedores, ao contrário dos consumidores, não operam por causa de seus critérios subjetivos de satisfação. Os proprietários ou responsáveis não agem buscando vivências prazerosas, mas segundo critérios objetivos, mensuráveis e concretos de retorno econômico; qualquer tipo de ofertante de mensagens, bens simbólicos ou bens materiais, necessita, no mínimo, que suas ofertas e produtos encontrem aceitação pelo público (SCHULTZE, 1997). Todas as empresas necessitam que suas ofertas e seus produtos satisfaçam as expectativas da clientela ou encontrem receptividade do público, do contrário, não subsistiriam por muito tempo no competitivo mercado capitalista.

Isso significa que tanto os indivíduos consumidores quanto os ofertantes seguem uma racionalidade moderna, que mobiliza os meios para a consecução de determinados fins. Apenas no caso dos consumidores, em busca das vivências sensacionais, essa operação não é tão linear e previsível, pois nem sempre os sujeitos têm clareza sobre o que querem, ou, depois de certo tempo, podem não alcançar o grau de satisfação anterior em relação à mesma oferta, a um mesmo local ou produto consumido. Daí a necessidade estrutural dos fornecedores de providenciar uma oferta incessante de atualizações, adaptações, variações e inovações, reais ou fictícias para seus produtos, de forma a manter a mesma expectativa de satisfação e prazer interior nos indivíduos.

Apesar de tanta ênfase nas escolhas individuais e nos critérios subjetivos, os coletivos - que não são mais a classe trabalhadora ou as grandes mediações coletivas do passado - continuam atuando como instância indispensável de orientação, de validação ou de constrangimento dos indivíduos. Segundo Schultze (1997, p. 35), a atitude fundamentalmente reflexiva do homem orientado para a sensação torna-o inseguro e produz nele uma prontidão para assumir procedimentos coletivos. A orientação fornecida pelos códigos simbólicos do grupo 
ou do meio social onde os indivíduos vivem habitualmente, ajuda-os a diminuir o risco de fazer escolhas "erradas” e decepcionantes. Mesmo assim, a insegurança e o risco de decepção permanecem no horizonte da experiência, não sendo possível preveni-los ou suspendê-los de todo. Insegurança, medo e risco pertencem estruturalmente ao horizonte da experiência contemporânea (BECK, 2010), e infelizmente não tem fortalecido a inserção das pessoas em comunidades abertas e solidárias, mas tem favorecido um uso instrumental das tribos urbanas e a segregação em "comunidades de estilo e de gosto". Esse uso instrumental e exterior dos coletivos, que funcionam como sinalização, validação e monitoramento cruzado dos indivíduos por seus “pares”, faz perceber que a noção de comunidade, tão cara às religiões e movimentos religiosos, recebe no processo de estetização da vida social uma configuração e um significado totalmente diferentes e inusitados.

Tanto para Nielsen como para Schultze, a estetização da vida cotidiana ainda não domina toda a complexa formação das identidades nas sociedades modernas, e nem se converteu num princípio universal. Certamente existem outros tipos de sociedade e cultura nas quais a sobrevivência, o dever, a dependência dos outros, a escravidão, o espírito de sacrifício, a tradição, a contemplação, a relação com o transcendente e a ligação profunda com a natureza são evidências que influenciam fortemente a concepção cotidiana de vida das populações. Nessas sociedades a busca por vivências intensas e emocionantes também acontece, mas não pertence ao objetivo central da vida das pessoas. Mesmo assim, a estetização da experiência tem se tornado sempre mais importante na organização da comunicação interhumana (NIELSEN, 2008, p. 9-10) e também da linguagem religiosa.

Com o processo de modernização e urbanização o mercado já havia tomado das religiões uma importante tarefa que antes lhes cabia, a de organizar e administrar as festas, o lúdico e o próprio ritmo do tempo da vida social. A modernidade deslocou a autoridade tradicional das religiões, que estava assentada na junção de uma temporalidade própria e geograficamente referenciada, ao separar e comprimir o tempo e o espaço (GIDDENS, 1991). Pode-se perguntar 
então, o que o processo mais recente da estetização "expropriou" das religiões, ou em que sentido ele as influencia? Será que o futuro da religião será o de transformar-se em estética?

\section{A religião sob o império da estetização}

O que expusemos acima sobre estetização da vida social se aplica também à religião, só que de forma mais complexa, pois toda religião se expressa esteticamente e a própria dimensão estética é constitutiva da experiência religiosa. Nesse sentido, a dimensão estética não é estranha, mas co-natural à própria experiência religiosa. Vejamos como isso se dá. A experiência mais arcaica que o cérebro humano guardou, que está por trás de toda síndrome de repetição, da própria linguagem, do sacrifício e, segundo Türcke (2010), do surgimento da própria consciência - e por tabela da humanidade da espécie - é a experiência que acometeu o homo sapiens de um pavor sem nome, de algo horripilante, talvez de um horrível crime primevo, que causou um excesso de excitação que o cérebro só conseguiu canalizar mediante uma compulsão traumática à repetição. $\mathrm{O}$ choque leva à repetição compulsiva e à busca de proteção junto ao que causa pavor; assim, o que salva do pavor é paradoxalmente ele mesmo. Esta foi a única forma de familiarizar-se com o pavoroso e aos poucos tomá-lo sob o próprio governo. O grito que escapa diante do indizível pavor e a memória traumática (ou cicatriz) que dele fica, são o início da consciência, da linguagem, da religião e da estética. Os rituais de sacrifício, a mais antiga forma recuperável de religião, que só muitos milênios mais tarde se desenvolveu, se inscrevem no esforço repetitivo, dramático e estético, de regularizar essa energia que vem do divino e auto imunizar-se contra seus possíveis efeitos devastadores. Uma energia que precisa ser canalizada e expressa para poder transformar o caos em cosmos dotado de sentido.

Dessa forma, nenhuma religião que se preze se reduz apenas a doutrinas e teologias, nem a relações de poder, nem a formas institucionais de organização, nem mesmo apenas a uma ética. Em graus diversos e segundo os contextos, as 
religiões incluem desde sempre também o ritual, a memória, o esconjuro, o ritmo, a cadência, a liturgia, a festa, a celebração, o silêncio e a espiritualidade. Frequentemente a experiência religiosa mais radical se dá justamente na forma do êxtase, do maravilhamento, da imersão ou da contemplação do sublime, da fusão com o divino, aquele mesmo que se manifestou como tremendum (OTTO, 1932). Em tudo isso religião e estética não são duas realidades separadas. A força do estético é a própria força da experiência religiosa, que se manifesta tanto como êxtase que chacoalha o corpo inteiro e a totalidade do ser humano, ou como a mais profunda concentração (=sintetização) e esvaziamento de si.

Ao tratar da estetização do religioso não estou me referindo à conaturalidade estrutural entre religião e estética, que se expressa históricamente numa diversidade enorme de formas singulares, mas sim a uma dinâmica sócio-cultural, inédita, de seqüestro e superinflação dos elementos estéticos da religião por parte da sociedade capitalista do espetáculo e de sua cultura do sensation seeking. Não se trata de dar expressões estéticas novas (ou "criativas") aos conteúdos religiosos (das igrejas), mas de transformar (ou reduzir) o próprio religioso a vivências sensacionais, emocionantes e prazerosas. Como vimos, a racionalidade econômica é a força maior dessa dinâmica que impõe às religiões uma gramática diferente da sua, uma reorganização dos seus elementos internos e que, no limite, escapa do controle do próprio universo religioso. A sociedade da sensação compele não apenas as instituições religiosas, mas também os indivíduos (que se tornaram sempre mais managers e gestores da própria religiosidade) a agir sistematicamente segundo expectativas subjetivas de desfrute, prazer e satisfação. A transformação sensacional do religioso atinge tanto formas religiosas que historicamente favoreceram expressões estetizadas, como o catolicismo, como aquelas que declaradamente evitavam mediações sensorial-estéticas, como o protestantismo e o pentecostalismo.

Mas como a estetização compulsória da vida cotidiana afeta e transforma as formas religiosas? Qual é a novidade que traz essa estetização do religioso? 
Aplicando a definição dada no início, podemos dizer que, do ponto de vista institucional, uma religião estetizada é aquela que usa de todos os meios para intensificar ("artificialmente") as percepções sensoriais, de modo a produzir emoções, comoção interna, experiências sensacionais e vivências arrebatadoras que por si mesmas não alcançariam tal intensidade. Nessa fase mais superficial, a religião estetizada sobrecarrega os aspectos sensoriais e emocionais dos seus ritos, espetaculariza-se e inflaciona a experiência religiosa com apelos estéticos, em detrimento de conteúdos doutrinais e exigências comportamentais. Numa fase mais avançada e "estruturante", que corresponde à estetização profunda mencionada por Welsch (2000), poderíamos dizer que uma religião sob o domínio da estética é aquela que reorganiza sua própria arquitetura interna (organização, práticas, doutrina, teologia), bem como suas expressões rituais e litúrgicas, para que elas se conformem aos objetivos de provocar e garantir experiências prazerosas e sensacionais. Ou seja, estetizada é aquela religião que como no mundo da simulação virtual - cria modelos, realiza simulações, torna elásticos e maleáveis seus elementos estruturantes e os remodela de modo a satisfazer as exigências da cultura da sensação e da racionalidade estetizante da formação social capitalista contemporânea. Seria uma religião que se tornou puramente evento-espetáculo (DEBORD, 1997).

Sem dúvida, exemplos da estetização superficial, que inflaciona liturgias, pessoas, rituais e lugares com apelos estéticos que obedecem à cultura do sensacional, os há em grande número. Difícil seria excluir, no campo religioso brasileiro, alguma modalidade de religião ou igreja que não a pratique. Veja-se, por exemplo, a indústria da música gospel, as megachurches, os shows-missa, a ritualidade triunfalista dos mega-templos, os mega-eventos papais, a obsessão por causar emoção e catarse nos fiéis, o cuidado obsessivo com vestes e decoração, o luxo de terreiros e locais de culto, a teatralidade ensaiada e, sobretudo, a produção "industrial" do próprio espetáculo religioso, no qual se usam sempre mais a alta tecnologia e os efeitos especiais e para o qual se contratam técnicos, artistas e profissionais que nada têm a ver com a religião. 
Quanto a exemplos de estetização profunda, pode-se avançar a hipótese de que algumas igrejas que seguem o padrão IURD já a atingiram. Indicadores importantes para isso seriam tanto sua estratégia de erros e acertos, sua prontidão para testar e introduzir no culto os mais diferentes elementos estéticos e aferir a reação do público, mantendo o que traz sucesso e eliminando o que não impressiona, como a reordenação elástica que fazem de elementos básicos da arquitetura interna do pentecostalismo tradicional. Além disso, a busca de adequação à cultura do sensacional nessas igrejas passa pelo planejamento estratégico e mercadológico, pelo investimento na indústria midiática, e pela reiterada prática pastoral e litúrgica de santificar as riquezas e o sucesso econômico. Algumas igrejas recentes, como a Church in Connection de AnápolisGO, por exemplo, dão mostras muito fortes de uma radical estetização da religião. Mas elas não são as únicas; estudos empíricos poderão comprovar até que ponto isso se verifica para outras modalidades de religião.

A expressão desalentada de Alavina (2012) já resume alguns traços atuais da estetização promovida a todo vapor pelas igrejas e grupos religiosos no contexto brasileiro:

$\mathrm{Na}$ atual forma de idolatria, aqueles que não fascinam, sucumbem. A fim de não sucumbir, a religião transforma-se em acontecimento midiático. Ao invés de se ir aos templos para participação em um ato litúrgico, assiste-se a um show... Na religiosidade estética dos novos tempos o profano torna-se sagrado, o discurso redentor da fé se reduz ao prazer daqueles que gozam uma satisfação estética disfarçada de espiritualidade. No divino submetido ao belo, o sagrado se estetiza e a religião torna-se estética... Se a estética dissolveu-se em nossas vidas cotidianas, a religião navega no mar de tal dissolução (ALAVINA, 2012).

Afinal, quais seriam as consequências de longo prazo do processo de estetização para essas religiões e igrejas, e para os movimentos religiosos em geral? Menciono apenas algumas: 
- O processo de estetização capitalista ao fornecer os quadros mais amplos e os próprios recursos estéticos para a experiência religiosa, pode estar relativizando e desestabilizando o núcleo ético-normativo das religiões;

- A progressiva estetização das religiões pode levar a uma neutralização do seu potencial performativo, mas também pode fortalecer iniciativas de leigos ou clérigos para reverter tais sintomas; ou seja, o processo pode favorecer o seu contrário, provocando movimentos fundamentalistas, reformadores ou proféticos;

- O investimento de muitas igrejas em plataformas interativas na Internet, onde os elementos estéticos predominam, deve favorecer a pulverização e o caráter aleatório dos laços entre fiéis e igrejas;

- As religiões reduzem complexidade através da veiculação estetizada da experiência religiosa, transformando as relações intangíveis em espetáculo ou vivências tangíveis. Contudo, isso pode redundar numa des-sensibilização para a própria linguagem estética da religião, favorecendo a sensação de vazio e, afinal, a própria secularização da experiência religiosa;

- As religiões e comunidades religiosas contribuem para a reposição da confiança num contexto social complexo e tardo-capitalista. Esta função torna-se extremamente frágil num cenário progressivo de estetização do trabalho simbólicoreligioso, pois as situações de decepção tendem a se acumular - seja em vista do desgaste acelerado do próprio capital simbólico, seja em vista da crise de credibilidade das instituições religiosas, seja ainda em vista da progressiva e cada vez mais patente impossibilidade de atender a tantos pedidos de milagre;

- As religiões do povo ("religiosidade popular"), pela falta de organicidade interna e de instâncias dirigentes, e ainda por serem ricas em elementos estéticos, devem ser sempre mais estetizadas e folclorizadas pelos agentes públicos e particulares responsáveis pelas políticas culturais, de turismo e outras. 
A estetização da religião também pode ser vista como uma hipertrofia da dimensão estética contida na experiência religiosa, mas que é moldada, exacerbada e conduzida a partir de uma referência exógena. No entanto, por ser levada a efeito por agentes que já internalizaram tal cultura, tanto o próprio fiel, gestor de sua constelação religiosa como, sobretudo pelos agentes das instituições religiosas, pode-se dizer que a estetização da religião também acontece “de dentro para fora”, pois numa ambiência que tudo envolve (a sociedade da sensação) há um reforço recíproco e concomitante entre os agentes. De todo modo, a esfera religiosa não consegue garantir seu controle e o processo é tocado também pelos agentes do mercado, sobretudo da publicidade, da mídia e do design, que podem saquear, manipular e vampirizar a componente estética das religiões, segundo suas necessidades de vendabilidade. Ou seja, nos processos em curso não creio que se trate de uma estratégia de adaptação das religiões a um universo cultural encharcado de estética, como forma "inteligente" de sobrevivência. Isto suporia que a religião nela mesma permaneceria mais ou menos idêntica e incólume, o que não acontece. A hipertrofia da dimensão estética passa a sobrepujar em muito a componente ética, intelectiva, o juízo moral e a auto-reflexão crítica, potencialmente presentes na experiência religiosa.

Se a estetização da vida cotidiana segue uma racionalidade instrumental, e nesse sentido agoniza um dinamismo ínsito à modernidade, sua potencialidade de expressão está ligada à expansão vertical da forma da mercadoria, mas não se reduz a ela. Quando a racionalidade dessa estetização é incorporada ao modus operandi normal das instituições religiosas e à economia psíquico-física das pessoas, essa forma estética aparece na experiência religiosa como aura sagrada da mercadoria, teatralização instrumental da força do símbolo, desperdício e desgaste acelerado da própria capacidade de simbolização da religião.

Por outro lado, no próprio movimento de estetização, tomado em si mesmo, existem também elementos anárquicos, arcaicos, não controlados, imprevisíveis e por isso com um potencial "libertário" e emancipatório que, conforme os contextos, podem agir como desestruturadores de sistemas religiosos fechados e autoritários. 


\section{Conclusão}

Tais reflexões não esgotam as possibilidades ou o potencial emancipatório da experiência e do discurso estético. Mesmo provisória, ou correndo o risco de ser re-funcionalizada, sempre será possível uma criação estética "desviante", uma linguagem estética das margens ou do reverso, ou pelo menos uma recusa da estética dominante. A condição necessária para isso será preservar a memória do heterogêneo, manter a lembrança do sofrimento e das promessas não cumpridas, realizar a celebração do descontínuo e da festa, cultivar as pequenas e grandes utopias. Há outras formas de estetização que resistem à instrumentalização e à lógica monolinear do mercado; para Nielsen a tendência instrumentalizadora seria uma variante específica da estetização capitalista, mas não a estetização nela mesma (NIELSEN, 2008, p. 12). Ao lado e por dentro da experiência cotidiana, organiza-se também uma experiência religiosa subsumida pela expressão "caminho do silêncio”, não apenas como protesto religioso, mas como desconfiança radical da gramática estética da religião funcionalizada e colonizada pela lógica do mercado. $\mathrm{O}$ pensamento e a trajetória de Marià Corbì oferecem nesse sentido uma contribuição lúcida e corajosa (CORBÌ, 1992). Esse caminho entrelaça-se com outras tradições, forma redes e mentalidades, impacta práticas sociais. Ao lado e por dentro das práticas estetizantes, o clamor de quem sofre na pele as conseqüências de um sistema desumano (ou idolátrico), que exige o sacrifício cruento das vítimas que produz, pode sempre de novo vertebrar experiências religiosas proféticas e não-conformistas.

Na verdade o discurso estético tem um potencial para prover a experiência humana de sensibilidade, diferenciação e sutileza, inclusão de grande alcance, muito mais do que o discurso puramente cognitivo ou moral poderiam oferecer (NIELSEN, 2008, p. 8). Se mobilizar uma reflexão sobre si mesma, a experiência estética pode quebrar formações rígidas de sentido, falar ao coração das pessoas e mobilizar suas energias e suas vontades para romper sistemas opressivos e idolátricos. Uma experiência religiosa emancipadora pode vertebrar um discurso estético que ajuda a crítica e produz bom-humor, mesmo em situações de opressão. 
Cada vez será preciso analisar se as práticas estetizadoras da religião favorecem a autonomia e a formação de sujeitos livres, ou se elas tornam o indivíduo um escravo das próprias fantasias estéticas e dos anseios de prazer. Nesse sentido, as comunidades religiosas precisam refletir sobre quais estilos de subjetividade elas estão reforçando e ajudando a estruturar.

Como afirma Seel (2007), não existe nenhum fim edificante intrinsicamente dado e garantido pela experiência estética. O estético por si mesmo não garante nenhuma emancipação, ele é constitutivamente aberto e polivalente. Isto faz com que evitemos definições totalizantes e definitivas desse fenômeno: a estetização da vida cotidiana e da religião é um processo conflitivo e aberto, no qual há lógicas monológicas e dialógicas, dinâmicas conflitantes e interesses em luta, tentando criar sentido, performar visões de mundo e, assim, alcançar hegemonia, no campo religioso e em todas as esferas da vida social. Falar sobre a estetização tem, portanto, um sentido processual: ela se refere menos a uma característica inerente da religião e muito mais ao modo pelo qual a religião está sendo transformada atualmente (BROMBACH, SETTON e TEMESVÁRI, 2010, p. 10). Como escreveu J. Rancière, "hoje em dia é no terreno estético que prossegue uma batalha, ontem centrada nas promessas da emancipação e nas ilusões e desilusões da história” (RANCIÈRE, 2005, p. 12).

\section{REFERÊNCIAS}

ALAVINA, Fran de O. A religião como estética: o divino submetido ao belo. O Povo, 07 jan. 2012. Disponível em:

<http://www.opovo.com.br/app/opovo/espiritualidade/2012/01/o7/noticiasjornalespirit ualidade,2370024/a-religiao-como-estetica-o-divino-submetido-ao-belo.shtml>.Acesso em: 02 jun. 2013.

BAUMAN, Zygmund. O mal-estar da pós-modernidade. Rio de Janeiro: Jorge Zahar, 1998.

BECK, Ulrich. Sociedade de risco: rumo a uma outra modernidade. São Paulo: Editorial 34, 2010. 
BENJAMIN, W. A obra de arte na era da sua reprodutibilidade técnica. 1. ed. Porto Alegre: Zouk, 2012.

BENJAMIN, W. Gesammelte Schriften. Ed. por Rolf Tiedemann und Hermann Schweppenhäuser. Vol. I. Frankfurt am Main: Suhrkamp, 1972.

BROMBACH, Ilka; SETTON, Dirk e TEMESVÁRI, Cornelia (Org.). Ästhetisierung - Der Streit um das Ästhetische in Politik, Religion und Erkenntnis. Zurique: Diaphanes, 2010.

CORBİ, Maria. Conocer desde el Silencio. Santander: Sal Terrae, 1992.

DEBORD, Guy. A sociedade do espetáculo. Rio de Janeiro: Contraponto, 1997.

DUFOUR, Dany-Robert. O divino mercado. A Revolução Cultural Liberal. Rio de Janeiro: Companhia de Freud, 2009.

DUFOUR, Dany-Robert. L'individu qui vient...après le libéralisme. Paris: Denoël, 2011.

FOUCAULT, Michel. Tecnologias del yo. In: Tecnologías del yo y otros textos afines. Barcelona: Paidós, 1990.

GIDDENS, Anthony. As consequências da modernidade. São Paulo: Ed. da Unesp, 1991.

LASCH, Christopher. The culture of narcissism. American life in an age of diminishing expectations. New York: Warner Books, 1979.

LEISS, William; KLINE, Stephen; JHALLY, Sut. Social Communication in Advertising. Persons, products \& images of well-being.2. ed. Londres: Routledge, 1997.

MOREIRA, Alberto da S. O futuro da religião na sociedade global: painel de um debate. In: MOREIRA, Alberto da S.; OLIVEIRA, Irene D. (Org.).O futuro da religião na sociedade global. São Paulo: Paulinas, 2008a. p. 17-35.

MOREIRA, Alberto da S. O deslocamento do religioso na sociedade contemporânea. Estudos de Religião, São Paulo, v. 22, n. 34, p. 70-83, jan./jun. 2008b.

MOREIRA, Alberto da S. A estetização da experiência religiosa. In: MOREIRA, Alberto da S.; LEMOS, Carolina T.; QUADROS, Eduardo G. (Org.). A religião entre o espetáculo e a intimidade. Goiânia: Ed. PUC Goiás, 2014. p. 299-317.

NIELSEN, Henrik K. The aestheticization of the public sphere and its consequences for democratic political culture. 2008. Disponível em: <http://socioaesthetics.ku.dk/uploads/HKNsocioaesth.pdf>. Acesso em: o1 nov. 2014.

OTTO, Rudolf. Das Heilige. 21. ed. München: C. H. Beck'sche Verlag, 1932. 
POSTMAN, Neil. Amusing ourselves to death. Public discourse in the age of show business. New York: Penguin Books, 1985.

RANCIÈRE, Jacques. A partilha do sensível: estética e política. São Paulo: Editora 34, 2005 .

SCHULTZE, Gerhard. Die Erlebnisgesellschaft. Kultursoziologie der Gegenwart. 7. ed. Frankfurt: Campus, 1997.

SEEL, Martin. Ästhetik des Erscheinens.Frankfurt am Main: Suhrkamp, 2007.

SIMMEL, Georg. Philosophie des Geldes [1900]. In: SIMMEL, Georg (Hrsg).

Philosophische Kultur. Frankfurt: a. M.: Zweitausendeins, 2008. p. 251-751.

TÜRCKE, Christopf. Sociedade excitada: filosofia da sensação. Campinas: Ed. da Unicamp, 2010.

WEBER, Max. Gesammelte Aufsätze zur Religionssoziologie. v. I-II. Tübingen: Mohr, 1922.

WELSCH, Wolfgang. Aesthetization processes: phenomena, distinctions and prospects. Theory, Culture \& Society, Nottingham, v. 13, n. 1, p. 1-24, 1996.

WELSCH, Wolfgang. Das Ästhetische - Eine Schlüsselkategorie unserer Zeit? In:

WELSCH, Wolfgang (org.). Die Aktualität des Ästhetischen. München: Fink, 1993. p. $13-47$.

ZAMORA, José A. Intimidad, Religión y Espetáculo. Caminhos, Goiânia, v. 12, n. 2, p. 279-311, jul./dez. 2014. 